\title{
Towards adopting serious games for cognitive tests with Brazilian older people
}

\author{
Leandro Agostini do Amaral \\ ICMC \\ University of São Paulo \\ São Carlos, Brazil \\ leandroagostini@usp.br \\ Paula Costa Castro \\ $C C B S$ \\ Federal University of São Carlos \\ São Carlos, Brazil \\ castro@ufscar.br
}

\author{
Renata Pontin de Mattos Fortes \\ ICMC \\ University of São Paulo \\ São Carlos, Brazil \\ renata@icmc.usp.br \\ Thiago Jabur Bittar \\ $D C C$ \\ University of Goiás \\ Catalão, Brazil \\ thiago.bittar@ufg.br
}

\author{
Marcos Hortes N. Chagas \\ $C C B S$ \\ Federal University of São Carlos \\ São Carlos, Brazil \\ setroh@hotmail.com \\ Luanna Lopes Lobato \\ DCC \\ University of Goiás \\ Catalão, Brazil \\ luannalobato@ufg.br
}

\begin{abstract}
Serious games are a promising tool in different scenarios, such as education and health; however, there has been little research reported on their specialized use for older adults. We created a digital cognitive test - with the characteristics of a serious game - using Unified Design aiming to reproduce digitally the results of clinical cognitive evaluation in older people. The digital cognitive test was submitted to two validation experiments targeting an older public $(n=40)$ with little experience in dealing with tablets or smartphones. The first experiment did not show significant correlation, but from it, we implemented initiatives to simplify the tests, which brought a positive result regarding convergence analysis in the second experiment. We concluded that it is possible to use digital games as cognitive tests adapted to the needs of older adults to achieve similar results as those of paper-based cognitive tests.
\end{abstract}

Index Terms-digital cognitive test, serious games, game accessibility

\section{INTRODUCTION}

The process of demographic transition, population ageing, is developed both in the world and in Brazil [1]. According to the Brazilian Institute of Geography and Statistics (IBGE) [2], $23.34 \%$ of the Brazilian population was age 50 and over in November 2017, in other words, approximately 48.5 million people. This percentage is likely to increase to $31.2 \%$ in 2030 , as reported by the same Institute, and it will grow progressively as the life expectancy rises. Due to better sanitary conditions and technological advances and health care, the causes of death migrated mostly from acute and transmissible causes to a higher prevalence of chronic and noncommunicable causes worldwide [3]. In Brazil we still face both conditions, but the epidemiological transition is also present with a high prevalence of these chronic diseases, such as the geriatric syndromes [4].

In this context, a great challenge faced by public health care is the higher prevalence of neurocognitive disorders/dementia.

The present study was supported by the grants 2016/01009-0 and 2017/14952-4, São Paulo Research Foundation (FAPESP).
According to the Global Dementia Observatory, about 50 million people suffer from dementia and there are almost 10 million new cases per year, six million of them in low- and middle-income countries [5]. In fact, Brazil has the second highest age-standardised prevalence of dementia [6], studies found rates varying between $5.1 \%$ [7] and $17.5 \%$ [8], being the point prevalence of dementia and of major neurocognitive disorder in 2018, 6.2\% and $8.1 \%$, respectively [9].

Dementias are a public health issue that raises bioethical concerns towards ageing: the loss of autonomy of affected people and the responsibilities of the public health system [10].

Ageing compromises especially the Central Nervous System (CNS), responsible for generate sensations, movements, psychological functions, and internal biological functions [11]. The integrity of the structure of neurons and neural pathways enables the CNS to retain information from both the present and the past, and to develop new concepts. Just as other biological systems, the CNS has properties that are able to reduce the effects of ageing, although they cannot always deal with all the adverse events of this process [11].

Even healthy ageing can cause cognitive alterations that may be associated with structural brain changes [12]. The most common alterations occur in the executive functions of the brain, in the episodic and working memories, in attention, and in perception [12], [13].

The executive function is a set of integrated abilities that allows a person to direct behaviours towards objectives, performing voluntary actions. These actions are auto-organized through an evaluation of their adequacy and efficiency in relation to the intended objective, which results in a selection of the most effective strategy, solving immediate and/or medium and long-term problems [14]. We use the executive function whenever we need to develop an action plan or when we must select and arrange a sequence of appropriated answers [15].

The episodic memory is a neurocognitive system that allows us to remember facts of the past. This type of memory is able 
to perform a "time travel" in which we recall events of our lives from the past to the present day [16].

The working memory represents a super-fast memory system (it lasts just a few seconds) that can retain, for example, a sequence of five to nine digits - long enough to remember a telephone number and dial it, but fast enough to forget it right after calling [15].

Attention "is taking possession of the mind, in clear and vivid form, of one out of what seems several simultaneously possible objects or trains of thought. Focalization, concentration of consciousness are of its essence. It implies a withdrawal from some things in order to deal effectively with others" [17].

Finally, perception is the process in which the brain selects, organize, and interpret stimuli, translating them into a significant and coherent image [18].

Cognitive decline may compromise the health of older adults, consequently causing the loss of functional capacity and autonomy, which decreases quality of life [19]. Cognition is a recognized and determinant factor of resilience and homeostasis in the human body, for the deterioration of the cognitive function may affect the preventive and therapeutic interventions [20].

As an alternative to slow down the natural damages to cognitive function caused by ageing, researches are being made about the benefic effects of digital games, which can revolutionize the clinical cognitive evaluation of older people, allowing these evaluations to be more frequent, accessible, and pleasant [21].

Therefore, in the present study we developed a cognitive digital test for older people with cognitive decline, and conducted empirical experiments aiming to answer the following research question:

Is it possible, through a digital game, targeting older adults, to have similar results to those of cognitive test batteries, commonly used by health professionals?

If this is possible, we intend, based on an analysis of the answers given by a user, to offer indicatives to direct this user to cognitive training games that exercise specifically his or her affected cognitive domains, or to dynamically adapt the mechanics of the games to the necessities of the player.

To answer the research question, we first investigated the main tools of existent cognitive tests, because they are paperbased validated tests. Then, we proposed a conversion of the cognitive test to a digital model, following the structured process for game design, namely Unified Design [22], thus prioritizing the usability of the target audience. We empirically tested the final prototype aiming to evaluate a possible convergence with the validated paper tests.

The present study contributes to the following areas: humancomputer interaction, gerontology, and health of older people, enabling an integrated vision that also emphasizes issues related to the acceptance by older adults of digital games and their potential benefits, which supports a healthy ageing and helps developing cognitive tests that are more efficient and recreational. Our conclusions suggest that it is possible to use digital games as cognitive tests for older people to achieve similar results as those of paper-based cognitive tests.

\section{Digital Cognitive Test for Older Adults - CONCEPTS}

In this section, we describe the concepts that are relevant to the present study. The papers we studied, based on published researches related to those relevant concepts, allowed the planning and development of a digital cognitive test for older people that is similar to cognitive test batteries, commonly used by health professionals.

In this context, we present the topics of serious games and their benefits; of cognitive evaluation and cognitive domains; and of a series of techniques to lower the barriers of the digital games environment, especially those related to the accessibility of older adults.

\section{A. Serious Games}

Many fields of study have approached the subject of games, such as education [23] and health [24]. From this segment in which entertainment is a low priority, arose the label "serious games".

Usually this expression refers to games that have an explicit and a carefully thought educative motivation; they are not supposed to be played just for fun or entertainment. Nevertheless, this interpretation does not mean that serious games are not or should not be amusing. In fact, they are projected to affect the target group in more ways than just entertaining [25]-[27], but the idea is that they can also be creative and pleasant elements.

One of the most important domains in which we can use serious games is education, for this field of study requires continuous improvement of techniques and renovation of educational resources [28]. Another recent initiative employing serious games is with older adults, which are a group of potential users who could benefit from playing digital games. It is possible to use these digital games to reduce the decline of some aspects of the body and the mind that are inherent in ageing, such as motor, perceptive, cognitive, and psychosocial aspects [29].

A research about different clinical situation of older people [30] revealed that serious games are an important tool to preserve and develop both social and cognitive skills. In addition, specialized literature shows that serious games for older adults may be an option to treat cognitive [31] and motor [32] impairment, to maintain a positive self-image, and to cultivate social interactions (improving affection and reducing solitude) [33].

A promising area to use serious games for older people is the neuropsychological evaluation, which consists of a detailed investigation of cognitive, sensorial, motor, emotional, and social functions to identify any neurological impairment and to determine preserved areas of the brain [34].

These games may offer other benefits inherent to computational cognitive tests [35], such as improvement of test standardization; better sources of data about performance (e.g., 
reaction time, latency, and variability); higher number of evaluated domains; greater sensibility; lower cultural bias; higher consistence among different clinical groups; better quality control and higher efficiency of data management; lower levels of stress; and greater sense of control to participants.

We justify our research about using serious games based on the studies above-listed. Therefore, we investigated the potential of these games for providing support to cognitive evaluation of older adults. In the next subsection, we describe the papers we studied about cognitive evaluation of older people.

\section{B. Cognitive Evaluation}

In global cognitive evaluation, most studies adopt brief cognitive rating scales, such as the widely used Mini-Mental State Examination (MMSE) [20]. It presents a score from 0 to 30 and it evaluates temporal and spatial orientation, memory (fixation and evocation), language, attention, and calculation [36]. In Brazil, many validation studies to determine the psychometric qualities of the MMSE were performed in different populations [37], [38].

Other instruments to evaluate the cognitive performance specially to the Brazilian population that were reported in literature are the following:

1) List of figures from the Brief Cognitive Screening Battery (BCSB): it uses images to evaluate memory. This test has six steps: naming, incidental memory, verbal fluency, clock drawing test, delayed recall, and recognition. It is accurate to be used on populations with a high number of illiterate or semi-illiterate people [39], [40];

2) Test of digit span (direct and reverse order) from Wechsler Memory Scale-Revised (WMS-R): it has seven pairs of numeric sequences, with a different number of digits. The test is administered in two orders: direct (sequences of three to nine digits) and reverse (sequences of two to eight digits) [41], [42]. The test ends after two wrong consecutive sequences, and we write the maximum number of correct repeated digits from each version (direct and reverse order);

3) Clock-drawing test (CDT): it is commonly used to investigate the impairment of cognitive skills, such as visuoconstructive and visuospatial perceptions, mental representation, writing skills, semantic memory, and executive functions. The score is from 0 (totally incorrect or inexistent clock) to 10 (totally correct). The test is currently validated for the Brazilian population [43], [44];

4) Semantic Fluency Test: it evaluates different cognitive domains such as language, semantic memory, and executive function. The examiner asks the participant to mention as many animals as possible within a minute. The evaluation depends on the level of education of the participant: the minimum required for people with up to eight years of formal education is nine; for individuals with more than eight years, it is thirteen [45];
TABLE I

NEUROPSYCHOLOGICAL INSTRUMENTS SEPARATED B Y NEUROCOGNITIVE DOMAIN.

\begin{tabular}{|c|c|}
\hline $\begin{array}{l}\text { Learning and memory } \\
\text { - List of figures from BCSB (1.) } \\
\text { - List of words from CERAD (5.) }\end{array}$ & $\begin{array}{l}\text { Motor cognition (visuospatial) } \\
\text { - Clock-drawing test (3.) } \\
\text { - Geometric shapes from CERAD } \\
\text { (6.) }\end{array}$ \\
\hline $\begin{array}{l}\text { Language } \\
\text { - Semantic Fluency Test (4.) } \\
\text { - Language items from } \\
\text { Mini-Mental }\end{array}$ & $\begin{array}{l}\text { Attention } \\
\text { - Direct and reverse digits (2.) }\end{array}$ \\
\hline $\begin{array}{l}\text { Executive function } \\
\text { - Semantic Fluency Test (4.) } \\
\text { - Clock-drawing test (3.) } \\
\text { - Subtest of similarities from } \\
\text { CAMDEX (7.) }\end{array}$ & $\begin{array}{l}\text { Social cognition } \\
\text { - Emotion Recognition Task (8.) }\end{array}$ \\
\hline
\end{tabular}

5) List of words from the CERAD Neuropsychological Battery: a list of words is presented and the participant must recall as many words as possible after each presentation. This procedure is repeated three times. After a while, the participant will have to remember those words and recognize them on a list of 20 words [46], [47];

6) Geometric shapes from the CERAD Neuropsychological Battery: it is a subtest from the CERAD neuropsychological battery [47], in which the patient must copy four simple geometric shapes [48];

7) Subtest of similarities from CAMDEX: it has four questions to evaluate the abstraction skills of participants from similarities between two things or objects, such as the similarity between an apple and a banana [49];

8) Emotion Recognition Task (ERT): it can be done using the Penn Emotion Recognition Test, in which the participant must recognize, through photos of facial expressions, the following basic emotions: happiness, sadness, anger, fear, disgust, or no emotion (neutral) [50].

We summarized the studied tests, separated by neurocognitive domains, according to the Diagnostic and Statistical Manual of Mental Disorders [51], in Table I.

When we consider the many advantages that older people can have from using serious games, including the cognitive evaluation, it is important to lower the barriers of digital technology. These barriers are the possible aspects related to cognitive declines that make it difficult for this older public to interact with dynamic application programs, as it is common on interactive systems of digital games.

Thus, it is imperative to respect the concept of accessibility (described below), which is inherent in one of the main quality attributes of Human-Computer Interaction (HCI) that is also related to usability of interactive system.

\section{Accessibility in Digital Games}

Although there is a growing interest in employing digital games in different fields of study, many people (including older adults) cannot use those games due to their special needs, 
such as visual, motor, hearing or cognitive impairment, or degenerative diseases [52]-[54].

We commonly use the International Classification of Impairments, Disabilities, and Handicaps (ICIDH), from the World Health Organization's (WHO) [55], to consider the range of limitations that may affect accessibility.

This classification encompasses the following impairments: visual, which is a vision loss that may be partial visibility, legally blindness, or total blindness; hearing, which refers to partial or total loss of the hearing ability and may occur in one or both ears; motor, which is the loss or limitation of muscular or movement control, or the limitation of mobility; cognitive, which represents a mental or psychological health problem that can vary from an impairment developed during childhood, to Alzheimer disease or senility as a result of ageing.

As the popularity of technology increases, greater are the efforts to understand the individuals with special needs and to make this technology accessible to them. For example, there is an effort on adapting the quality criteria of software towards accessibility, which contributes to the adoption of practices and functionalities incorporated to operational systems, such as screen readers or accessibility shortcuts. The same changes happened to the Internet in the 1990s, allowing a shift in researches that made the World Wide Web and the technologies related to it accessible.

A consequence of this shift is the Web Accessibility Initiative (WAI), which prepared a document, the Web Content Accessibility Guidelines (WCAG), through the Wide Web Consortium (W3C) process [56], in collaboration with people and organizations from all over the world [57].

The guidelines of WCAG direct the content production for the Internet (texts, images, forms, and sounds), making it accessible to people with different special needs, including partial or total visual impairment; partial or total hearing loss; learning difficulties; cognitive limitations; movement limitations; speech impairment; photosensitivity; and their combinations [57].

Since the beginning of the Internet, many definitions about accessibility were presented. A comparative study [58] about the semantic similarities among them intended to create a broad definition, which can also be used in the context of digital games: "all people, particularly disabled and older people, can use websites in a range of contexts of use, including mainstream and assistive technologies; to achieve this, websites need to be designed and developed to support usability across these contexts", in which we can replace "websites" for "digital games". However, the specific characteristics of accessibility in digital games require guidelines that take into account their functional, technological, and differential aspects.

The increasing popularity of digital games will probably boost the focus on works and researches that promote accessibility, but there are still few efforts in this area [59]. There are neither official guidelines, nor global standards and initiatives, nor governmental or legislative propositions that can be compared to the WCAG in the context of digital games.
Nevertheless, there are two interventions aiming to obtain this directive collection: the first was published in 2004 and updated in 2010 by the Special Interest Group (SIG), from the Independent Game Developers Association (IGDA), and it proposes 19 accessibility guidelines from an experiment with 20 games, prioritizing users with visual impairment [22]; the second one, which is based on the 19 directives from IGDA, was also published in 2004, by the Norwegian company MediaLT, and it is a collective of 34 accessibility guidelines [60].

In 2012, there was a collaborative effort between producers, experts, and scholars to conceive an objective reference for game developers that would allow the inclusion of as many people as possible, considering the different needs of every disabled person, which created the game accessibility guidelines [61]. These guidelines are categorized in three sets: basic, intermediate, and advanced. They contemplate the number of people who benefit from them, the impact on the lives of those people, and the cost to implement them [61]. The guidelines are also divided in subgroups of abilities (and impairments): motor, cognitive, vision, hearing, and speech.

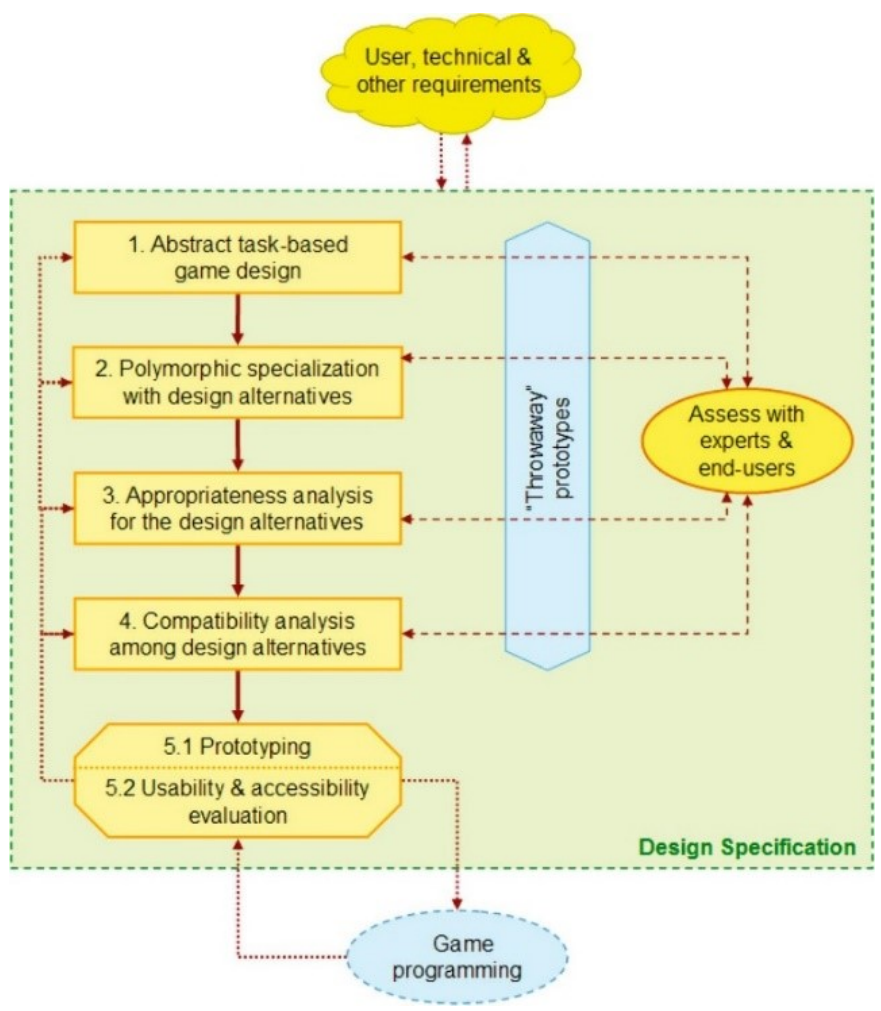

Fig. 1. Steps of Unified Design for universally accessible games. (From [22])

Among with the establishment of the internationally recognized game accessibility guidelines, there is an improvement in the quality of games caused by the creation of a structured process of game design, namely Unified Design [22]. One of the steps of this Unified Design is to evaluate technical accessibility, which can verify the use based on the guidelines and appeal to expert participation and final users in all stages 
of a game development, as we can see in Figure 1.

The Unified Design, as described in [62], allows creating the game design independent of the technological characteristics of the development context. This means projecting the game on an abstract level, which diminishes the references to interactions, gadgets, and techniques that employ a specific modality. The resulting design may be specific to a certain user or group of users (user profile), intending to meet their particular needs of interaction.

The use of Unified Design in this project was present since the conception of the games, with the support of experts, such as researchers and a doctor collaborating and evaluating the tasks that the elderly should perform, according to the cognitive domain under analysis, based on traditional cognitive tests.

The design focused on the elderly audience with mild cognitive decline. The accessibility guidelines ${ }^{1}$ for this audience, considered during development, were: offer sound alternatives, high visibility graphics, color-blind friendly design, accessible menus, standard text presentation and better in-game tutorials.

\section{METHOD}

This is a cross-sectional, descriptive, and analytical study based on a qualitative and quantitative investigation. The research was performed in the city of São Carlos, in São Paulo state, Brazil.

To create the cognitive digital test, we used the Unified Design on the analysis phase, and the Integrated Development Environment (IDE) Stencyl ${ }^{2}$ on the development phase. We chose the IDE because it facilitates the creation of a prototype, which makes it ideal for projects of little to moderate complexity.

We chose a tablet as the final device, for it is a reliable and efficient tool for older adults to use. Because this group of people may have psychomotor and visual impairments, this gadget offers more accessibility to the digital world, which helps overcoming barriers of psychomotor difficulties [63].

As we aimed to compare brief cognitive rating scales to a digital test, we developed a prototype of the digital cognitive test (described in Section IV), which was administered to a group of 17 older adults. Then, we adapted the prototype and administered it to another group of 23 older people, different from the first group.

The criteria for selecting the participants were the following: older people of both sexes aged 60 and over [64] that had some experience with tablets or smartphones, for the study intends to lower the barriers of digital technologies (specifically games) and the lack of knowledge could affect the results. Additionally, the participants could not be visual or hearing impaired so that the test could not be performed, and could not have been diagnosed with psychiatric disorder or dementia.

After the research explanation, we administered the test to the participants who accepted the invitation to be part of the

\footnotetext{
${ }^{1}$ https://igda-gasig.org/about-game-accessibility/ guidelines/

${ }^{2} \mathrm{http}: / /$ stencyl.com/
}

TABLE II

QUESTIONS ASKED DURING THE INTERVIEW.

$\begin{array}{ll}\mathbf{1} & \text { What is your name? } \\ \mathbf{2} & \text { What is/was your profession? } \\ \mathbf{3} & \text { Tell us a story you like. It may be a book you've read, a chronicle, } \\ & \text { a tale, a play you've seen, a movie, etc. } \\ \mathbf{4} & \text { When did you read/heard this story? } \\ \mathbf{5} & \text { Can you describe the feeling that this story evokes in you? } \\ \mathbf{6} & \text { Is/was it a part of your quotidian to tell stories? How? } \\ \mathbf{7} & \text { Nowadays, do you follow any story like TV series, books, or } \\ & \text { movies, for example? Do you have a favorite category? } \\ \mathbf{8} & \text { Name some singers that were central to your life at any age. Do } \\ \mathbf{9} & \text { you still listen to some of them? } \\ \mathbf{1 0} & \begin{array}{l}\text { Do you listen to music nowadays? To which singers? } \\ \text { It can be antion an activity: swimming, playing soccer, sewing, etc. }\end{array}\end{array}$

study after they signed the Informed Consent Form (ICF). The experiments were approved by the ethics committee of USP / FZEA (CAAE 05299218.1.0000.5422).

Both groups were composed by people that are part of the Tablets and Smartphones Practice Classes, from of the Third Age in the Open University Project, at USP, inclusion with weekly lessons. In this course, they learn how to use basic tools of mobile devices such as apps (e.g. WhatsApp, Facebook, Google Photos, E-mail) and configuration. Therefore, the participants were a sample of Brazilian older people that has some experience with mobile devices and that has shown interest in learning how to use those gadgets.

We administered the following evaluations to the first group, respectively: (i) Mini-Mental State Examination (MMSE); (ii) List of figures from the Brief Cognitive Screening Battery (BCSB); (iii) Test of digit span (direct and reverse order); (iv) Subtest of similarities from CAMDEX; (v) List of words from CERAD; (vi) our digital cognitive test; and (vii) an interview (Table II). Since the cognition is affected by various factors (e.g. time of the day, fatigue, etc.) [65], we conducted the digital cognitive tests shortly after the other tests. All of these tasks together took approximately two hours.

Based on the interviews, we characterized the sample in relation to preferences and personal tastes. After the tests and the interview, all participants from the first experiment answered a User Experience Questionnaire (UEQ), which evaluates the feelings, impressions, and attitudes of the user when interacting with an interface, so we could quantify and analyze the user experience in relation to this interface.

The UEQ comprises scales that evaluate the attractiveness, perspicuity, dependability, efficiency, novelty, and stimulation that an interface can offer users. Attractiveness evaluates if aesthetics and design are able to attract the user; perspicuity, if the interface is easy to comprehend and learn about; $d e$ pendability evaluates if the interface is predictable and secure; efficiency, if the interface is fast and organized; novelty, if the interface is creative and innovative; and stimulation evaluates if the interface is interesting and keeps the user interested.

The scales can be grouped in pragmatic quality (perspicuity, efficiency, and dependability), related to quality aspects of the task, and hedonic quality (efficiency and novelty), quality 
aspects not related to the task [66].

The correlation between the paper-based and the digital tests was analyzed using the Spearman Correlation, from a statistic analysis, using the IBM SPSS Statistics 21.0. The significance level considered was $\mathrm{p}<0.05$.

Elderly interaction data is stored in a JSON file on the device itself. At the end of the study with the elderly, we sent the file by the interpreter: http://pipe.aptor.software, developed especially for the digital cognitive test and analyzed the time spent on each task, the hits, errors, and other measures cited in Table IV.

\section{Digital Cognitive Test Prototype}

We considered usability and accessibility from the beginning of the present study in order to identify and project the most appropriated interface for older people.

We used the Unified Design and we studied different researches about the best way to evaluate accessibility in digital games, especially when related to older adults. In these studies [67], [68], we describe how the usability study, based on different heuristics and with the participation of older people, provided measures to improve the interface and interactive functions of the digital cognitive test described here.

Design focused on the elderly audience with even a slight cognitive decline. The main accessibility guidelines for digital games considered for this audience from the set of guidelines seen in the 61, during development, are highlighted in Table III.

With respect to the defined guidelines [69], given the previously defined end user features: $(a)$ offers sound alternatives, (b) high visibility graphics, (c) design color-blind friendly, (d) access menus, $(e)$ standard presentation menus, $(f)$ standard text presentation, and $(g)$ best tutorials in the game.

An example of a decision made during the development process (besides the observation of the accessibility guidelines listed in Section II-C) is the choice of a color palette that could include color-blind people, specifically those that have Tritanopia, Protanopia, or Deuteranopia. We used the Color Oracle tool to simulate these three visual impairments, and then we eliminated the colors that in one or more cases were too similar to each other, which made them almost identical. Additionally, we were careful to create the assets of the game, for feedbacks and goals cannot count only on color to be distinguishable; therefore, we also used sounds and shapes.

In the battery of cognitive tests, nine aspects were investigated: 01 - Visual Perception, and Incidental and ShortTerm Memory; 02 - Praxis; 03 - Abstraction; 04 - Visual Perception, and Incidental and Short-Term Memory; 05 - Test of digit span (direct order); 06 - Test of digit span (reverse order); 07 - Attention; 08 - Semantic Fluency Test; and 09 - Facial Recognition. These aspects were studied to verify a possible correlation with paper-based tests intending to convert those tests into digital games without any significant alteration in the context.

Therefore, we defined how we would contrast the interaction elements of both tests (paper-based original versus digital
TABLE III

Game AcCessibility Guidelines (GAG) USED

\begin{tabular}{|l|}
\hline \multicolumn{1}{|c|}{ General } \\
\hline Offer a wide choice of difficulty levels \\
\hline Include some people with impairments amongst play-testing participants \\
\hline \multicolumn{1}{|c|}{ Motor } \\
\hline Allow controls to be remapped / reconfigured \\
\hline Ensure controls are as simple as possible, or provide a simpler alternative \\
\hline $\begin{array}{l}\text { Ensure interactive elements / virtual controls are large and well spaced, } \\
\text { particularly on small or touch screens }\end{array}$ \\
\hline $\begin{array}{l}\text { Make interactive elements that require accuracy (eg. cursor/touch con- } \\
\text { trolled menu options) stationary }\end{array}$ \\
\hline $\begin{array}{l}\text { Ensure that multiple simultaneous actions (eg. click/drag or swipe) are not } \\
\text { required, and included only as a supplementary / alternative input method }\end{array}$ \\
\hline Avoid repeated inputs (button-mashing/quick time events) \\
\hline \\
\hline $\begin{array}{l}\text { Allow the game to be started without the need to navigate through multiple } \\
\text { levels of menus }\end{array}$ \\
\hline Use an easily readable default font size \\
\hline Use simple clear language \\
\hline Use simple clear text formatting \\
\hline Include tutorials \\
\hline Allow players to progress through text prompts at their own pace \\
\hline Avoid flickering images and repetitive patterns \\
\hline Include contextual in-game help/guidance/tips \\
\hline Indicate / allow reminder of current objectives during gameplay \\
\hline Indicate / allow reminder of controls during gameplay \\
\hline Employ a simple, clear narrative structure \\
\hline $\begin{array}{l}\text { Ensure no essential information (especially instructions) is conveyed by } \\
\text { text alone, reinforce with visuals and/or speech }\end{array}$ \\
\hline Avoid any sudden unexpected movement or events \\
\hline \\
\hline Ensure no essential information is conveyed by a colour alone \\
\hline Use an easily readable default font size \\
\hline Use simple clear text formatting \\
\hline Provide high contrast between text/UI and background \\
\hline $\begin{array}{l}\text { Ensure interactive elements / virtual controls are large and well spaced, } \\
\text { particularly on small or touch screens }\end{array}$ \\
\hline $\begin{array}{l}\text { Avoid placing essential temporary information outside the player's eye- } \\
\text { line }\end{array}$ \\
\hline \\
\hline Ensure no essential information is conveyed by sounds alone \\
\hline played any subtitles / captions are used, present them in a clear, easy to read \\
\hline Provide subtitles for supplementary speech \\
\hline
\end{tabular}

model), as seen in Tables IV and V. All original tests, listed here and digitally adapted to address exercise tasks of the same cognitive domain, were based on the instruments mentioned in Section II and were chosen considering the recommendations of the Brazilian Academy of Neurology [70], to cover most of the neurocognitive domains listed in Table I, are in portuguese language, since they are commonly used and validated in Brazil.

It is noteworthy that the adaptations were made prioritizing the cognitive domain and not exactly the test task on which they were based, since the objective was not to copy the tests fully to the digital environment, because in some cases, the computational analysis would be difficult, compared to other possible variations that could provide the same result. Another justification for the care of not transposing them directly to the digital environment is the fact that no licenses were found that 
would allow the pure use of traditional batteries.

An example of computational difficulty avoided in this validation phase refers to speech recognition for the transcription of spoken language automatically. Such functionality culminates in a vast field of research to be explored when considering the Portuguese language and the elderly user as a context of application.

In addition to the computational difficulty involved, the use of speech recognition is limited by the accessibility guidelines [61], as it is represented as an alternative, non-mandatory input method, and a small monosyllabic vocabulary should be prioritized.

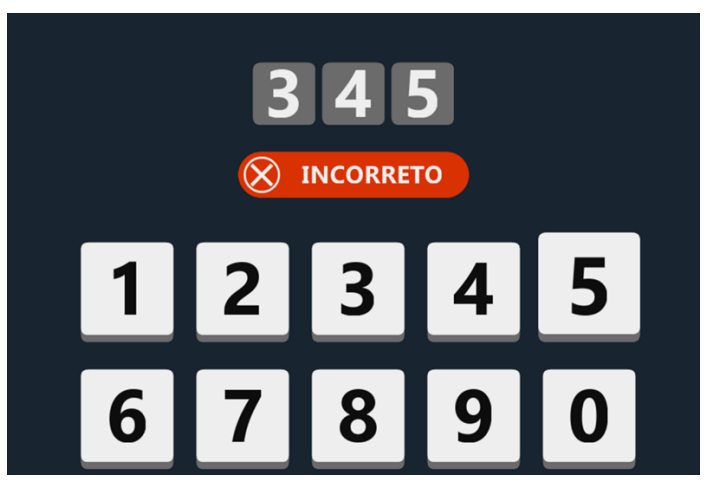

Fig. 2. Print screen of an incorrect answer of a sequence of numbers.

To each test, measures were obtained (assigned to variables) as seen in Tables IV and V. These measures were collected during the interaction process of the participant and were used in the final phase of the convergence analysis (with the paper-based tests). The main objective of these variables is to represent the result of each test and to allow running the computational analysis - without human perception, to inhibit bias of the researcher.

A video demonstrating the execution of the digital cognitive tes can be seen at: http://leandroagt.com.br/video.mp4.

\section{EMPIRICAL EXPERIMENT}

In the first experiment, (Subsection V-A), we considered all nine tests described in Tables IV and V. We then decided to reduce the number of tests on the second experiment (Subsection V-B) because of the time needed to complete all of them (around two hours) - time including traditional tests, together with digital and UEQ respectively -, the feedback of participants, and the possible interferences of fatigue on the results.

\section{A. The First Experiment}

We evaluated 17 subjects, predominantly women (76.5\%). Their median age was of 70.12 years and their average education level was of 14.23 years $(47.1 \%$ had a college degree). Most of the participants were retired $(82.2 \%)$ and married $(58.8 \%)$.
TABLE IV

CORRELATED ELEMENTS BETWEEN PAPER-BASED TEST AND DIGITAL MODEL.
01 - Visual Perception, and Incidental and Short-Term Memory

Original I will tell you the name of three objects and when I finish, I will ask you to repeat them, in any order. Save them later I'll ask again: Tree, Table, Dog.

Digital The tablet screen, in landscape orientation, exhibits a 5x5 matrix with 8 blue squares, randomly distributed. The user has 10 seconds to memorize the disposal of the squares and cannot skip this image. Then, the user must fill an empty $5 \times 5$ matrix with the same disposal. Touching an empty space transforms it into a square; touching a square removes it. The participant has 30 seconds to complete the task. The task is repeated another two times. Considered measures: number of correct and wrong answers from eight possibilities, which results in a score as a percentage of the right answers.

\begin{tabular}{ll}
\hline \hline O2 - Praxis \\
\hline Original & The participant must draw four geometric shapes. \\
\hline Digital & The tablet screen, in landscape orientation, exhibits an \\
& image in shades of grey on the right. On the left, the user \\
& has a series of pieces to move and put together in order to \\
& assemble the image. To move a piece, the user must touch \\
& it and drag it. To complete the task, the participant must \\
& select CONFIRM. Then, the user must do this task another \\
& two times, with different images. The pieces are the same \\
& as in Tangram [71].
\end{tabular}
as in Tangram [71].

\begin{tabular}{ll}
\hline \hline O3 - Abstraction \\
\hline Original & $\begin{array}{l}\text { I will name two things and I would like you to tell me how } \\
\text { these two things are similar, what they have in common. } \\
\text { For example, a dog and a monkey are similar because they } \\
\text { are both animals. }\end{array}$ \\
\hline Digital & The tablet screen exhibits four images: three are related \\
& (e.g., three fruits) and one is not. The user must touch only \\
the figure that is not related to the others. Selecting an \\
object starts a new sequence. The task is repeated three \\
times. Considered measures: the right answers. The score \\
is 100 when the correct image was selected, and 0 if it was \\
a wrong one.
\end{tabular}

04 - Visual Perception, and Incidental and Short-Term Memory

Original After some time, I'll ask what were the three objects spoken in 01 .

Digital Another empty $5 \times 5$ matrix is presented to the user, who must fill it with the same disposal of task 01. The participant has 30 seconds to complete the task. Considered measures: number of correct and wrong answers from eight possibilities, which results in a score as a percentage of the right answers.

\begin{tabular}{ll}
\hline \hline O5 - Test of digit span (direct order) \\
\hline Original & $\begin{array}{l}\text { I will read some numerical sequences and I want you to } \\
\text { repeat the numbers of each sequence in the same order. }\end{array}$ \\
& The tablet screen, in landscape orientation, exhibits three \\
& random digits (Fig. 2), which cannot be the same. Each \\
& number is shown for one second, then a new image appears: \\
& three empty boxes on the superior part of the screen, and \\
& bellow them, a reduced virtual keyboard that has digits \\
& from 0 to 9 and a backspace button. The user must select \\
& the numbers in the same sequence that was shown before. \\
& When the third digit is inserted on the last box, another \\
& sequence of 3 digits is presented. Another digit is added \\
& every two sequences. The tasks ends when the user gets \\
& wrong two consecutives sequences with the same amount of \\
digits. If the user does not mistake any digit, the sequences \\
raise until they reach 9 digits. Considered measures: the \\
highest number of direct sequences correctly typed.
\end{tabular}


TABLE V

CORRELATED ELEMENTS BETWEEN PAPER-BASED TEST AND DIGITAL MODEL (CONT.)

\begin{tabular}{|c|c|}
\hline \multicolumn{2}{|r|}{07 - Attention Test } \\
\hline Original & $\begin{array}{l}\text { Using a pencil, connect all numbers in the correct order, } \\
\text { from } 1 \text { to } 9 \text {. }\end{array}$ \\
\hline Digital & $\begin{array}{l}\text { The user must connect numbers from } 1 \text { to } 9 \text {. When a } \\
\text { number is touched, the position of the others changes. After } \\
\text { touching all of them, the task ends. Considered measures: } \\
\text { number of right sequences and time taken to do the test. }\end{array}$ \\
\hline \multicolumn{2}{|r|}{08 - Semantic Fluency Test } \\
\hline Original & $\begin{array}{l}\text { "You must say aloud all the animals (any animal) that you } \\
\text { can remember in the shortest possible time". Note down the } \\
\text { number of animals the patient remembered in one minute. }\end{array}$ \\
\hline Digital & $\begin{array}{l}\text { A limited digital keyboard is presented to the user, who } \\
\text { has to write all the names of animals he or she can recall. } \\
\text { Every time the user writes a name, he or she must select } \\
\text { CONFIRM to be able to write another name. The task ends } \\
\text { automatically after one minute or if the user selects EXIT. } \\
\text { Considered measures: number of correct names. }\end{array}$ \\
\hline \multicolumn{2}{|r|}{09 - Facial Recognition } \\
\hline Original & $\begin{array}{l}\text { Photos selected from the series of Ekman and Friesen } \\
\text { that represent six basic emotions (happiness, sadness, fear, } \\
\text { surprise, anger, and disgust) will be used. Four pictures of } \\
\text { four different actors represent each emotion: two of each } \\
\text { at an intensity of } 30 \% \text {, and the other two, of } 70 \% \text {. There } \\
\text { are also two pictures of neutral faces, totalizing } 26 \text { photos } \\
\text { presented randomly. The seven possible answers are printed } \\
\text { and disposed on a circular shape so the participant can } \\
\text { chose one of the options. }\end{array}$ \\
\hline Digital & $\begin{array}{l}\text { The tablet shows a picture of an emotion in the center of } \\
\text { the screen. Around it, there are seven possible answers to } \\
\text { name that emotion. The player's answer is submitted right } \\
\text { after the participant touched one of the options, which ends } \\
\text { the task for that photo and starts a task for another one, } \\
\text { until the user classifies } 12 \text { pictures. Considered measures: } \\
\text { selected answer representing the name of the emotion. }\end{array}$ \\
\hline
\end{tabular}

\section{B. The Second Experiment}

In the second experiment, we considered only two of the first tests: 01 - Visual Perception, and Incidental and ShortTerm Memory; and 02 - Praxis. However, on test 01, the explanation was improved and, on 02, instead of repeating the same task three times, they did it only once.

We also developed a third digital test (Fig. 3) based on the Revised Beta Examination - Third Edition (Beta-III). They were chosen because their digital representation is easy and requires little adaptation, aiming to influence less possible results, since the aim here is to verify the convergence of the digital tests with the paper based ones, which are mutually validated.

Beta-III is a nonverbal assessment of intellectual abilities used as an instrument to estimate the level of intelligence of adults or children of several education levels. This test aims to evaluate the abstraction skills, the ability to solve new problems, and the speed of thought. The Brazilian adaptation of this test was performed only in two subtests: Codes, and Matrix Reasoning [72]. The Matrix Reasoning Subtest was selected for the presented study and it evaluates visual information processing and abstract reasoning.

To measure the attention of individuals, we selected the Trail Making Test (TMT), created by Partington, in 1938, as a tool to evaluate divided attention [73]. We adapted the TMT to a digital format (Figure 4).

In the second experiment, we evaluated another 23 subjects; $78.26 \%$ were women and $22.74 \%$, men. Their median age was of 68.56 years. Most of the participants were retired (65.21\%) and married $(52.17 \%)$ or widowed $(26.08 \%)$, and their average education level was of 9 years $(21.74 \%$ had a college degree).

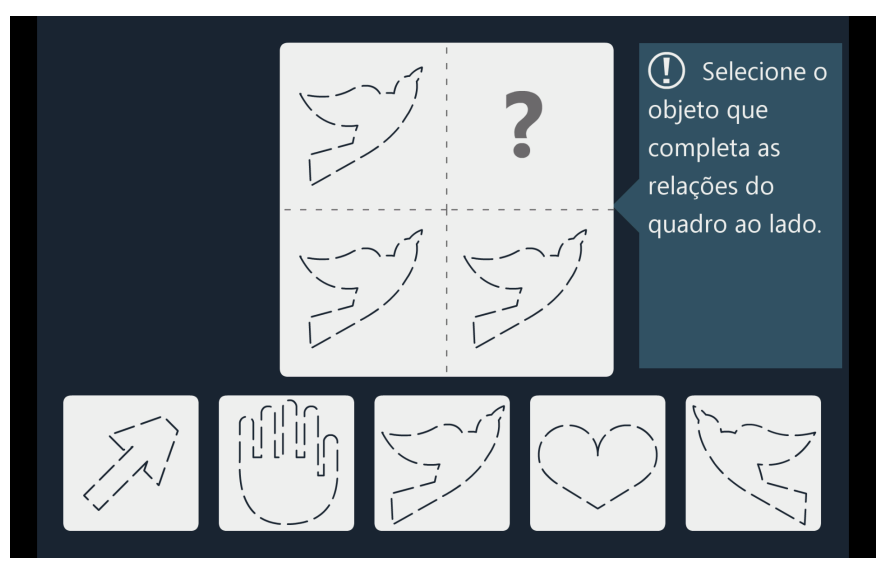

Fig. 3. Test based on Beta-III.

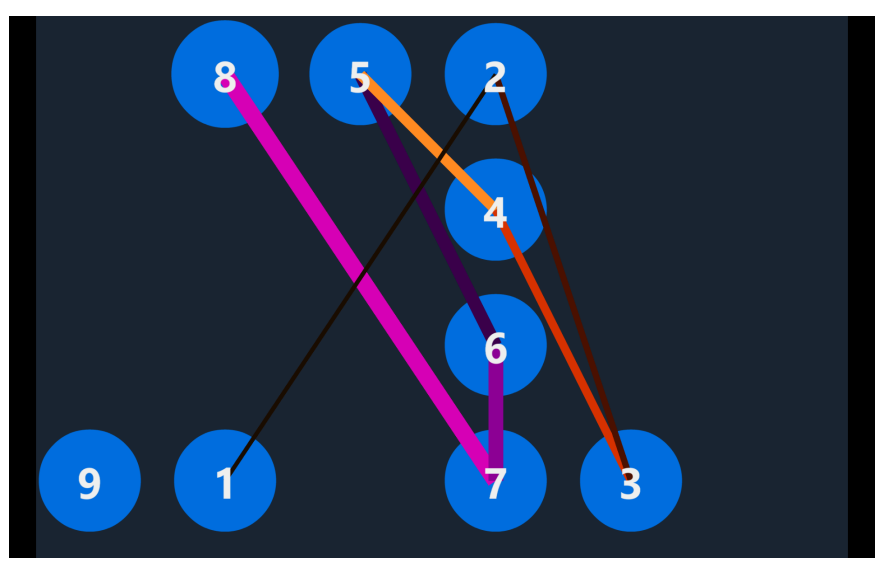

Fig. 4. Test based on Trail Making Test (TMT).

\section{RESUlTS}

After submitting the participants to all tests in both experiments, the data were collected, tabulated, and analyzed. We intended to identify a possible convergence to answer the research question (Section I).

From the impressions we had after the first experiment, we adapted the digital game to reduce the time needed to administer it and to offer more aligned tests to the paper-based ones, mirroring them in a digital context.

\section{A. Results of the First Experiment}

Based on the feedback of the users on the UEQ after the first experiment, we observed that the best evaluated scales for the digital test were those related to attractiveness, efficiency, 
and stimulation. On the other hand, perspicuity, dependability, and novelty had lower scores (Figure 5).

When analyzing the group according to pragmatic quality, hedonic quality, and attractiveness, we noticed that only attractiveness had a better score, whereas the other groups were just a little bit above the average (Figure 6).

Although our research was composed by subjects that had previous experience using mobile devices, had a medium to high level of education, and had a satisfactory user experience in digital tests, we did not observe a strong correlation between validated tests and digital tests in the first experiment (Figure 7). Only 6 out of 88 values on Figure 7 (6.81\% - highlighted on the figure) showed any correlation $(r>0.5$ e $p<0.05)$.

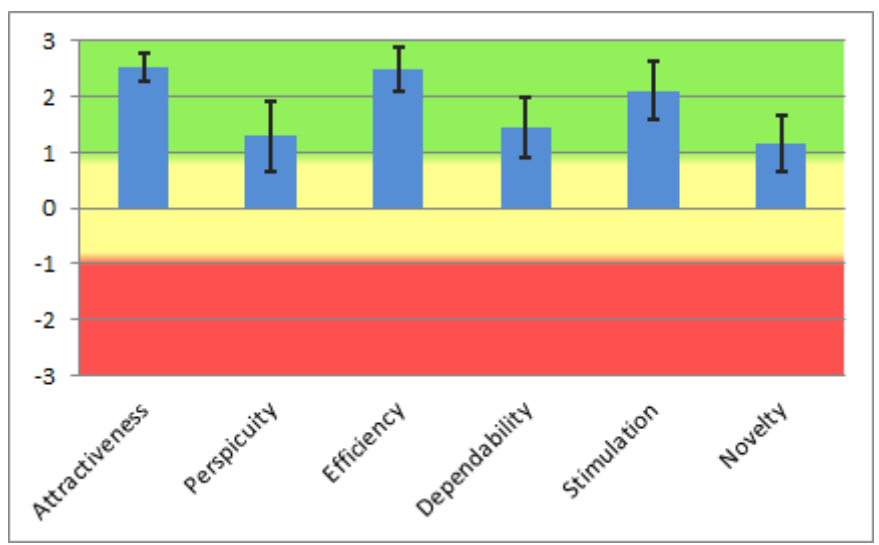

Fig. 5. UEQ Scale Results.

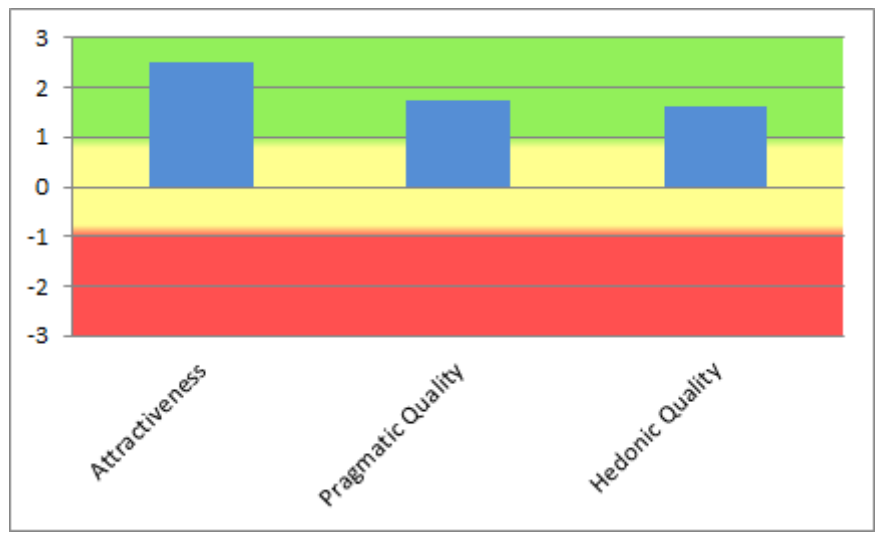

Fig. 6. TUEQ group results.

One of the reasons for the lack of convergence was the expectation of success or failure that the participants felt during evaluation. According to one study [74] that analyzed the motivations of older people in using digital games, this expectation happens and must be carefully considered. It comes from anxiety and it can jeopardize their performance during game even more than cognitive impairments [74]. During the data collection process, we observed this anxiety many times when the participants expressed themselves: "I wonder if I got it right"; "Am I doing good in the game?";
"Did I win?"; "I think I can't make it, I'm not as I used to be."

As in the attention test, in the digital cognitive test, all the respondents had good results and the like, this neurocognitive domain was disregarded in comparison with the batteries of cognitive tests.

\begin{tabular}{|c|c|c|c|c|c|c|c|c|}
\hline & \multicolumn{8}{|c|}{ Digital cognitive test } \\
\hline & $\begin{array}{c}\text { Total } \\
\text { memory }\end{array}$ & $\begin{array}{l}\text { Late } \\
\text { memory }\end{array}$ & Praxis & $\begin{array}{c}\text { Abstracti } \\
\text { on }\end{array}$ & $\begin{array}{l}\text { Direct } \\
\text { Digit }\end{array}$ & $\begin{array}{c}\text { Reverse } \\
\text { digit }\end{array}$ & $\begin{array}{l}\text { Semantic } \\
\text { fluency }\end{array}$ & $\begin{array}{c}\text { Facial } \\
\text { recogniti } \\
\text { on }\end{array}$ \\
\hline \multirow{2}{*}{ MMSE } & $r=-0,083$ & $r=0,550^{\circ}$ & $r=0,326$ & $r=-0,300$ & $r=0,169$ & $r=0,257$ & $r=0291$ & $r=0,101$ \\
\hline & $p=0,761$ & $p=0,0<7$ & $p=0218$ & $p=0,258$ & $\mathrm{p}=0,532$ & $p=0,337$ & $p=0274$ & $p=0,709$ \\
\hline \multirow{2}{*}{$\begin{array}{l}\text { Word list } \\
\text { memory } \\
\text { CERAD }\end{array}$} & $\mathrm{r}=0,044$ & $r=0,287$ & $r=0,496$ & $r=0,001$ & $r=0,155$ & $r=0,311$ & $r=0,371$ & $r=0,4$ \\
\hline & $p=0,871$ & $p=0,282$ & $p=0,051$ & $p=0,997$ & $\mathrm{p}=0,568$ & $p=0,241$ & $p=0,157$ & $p=0,125$ \\
\hline \multirow{2}{*}{$\begin{array}{c}\text { Figures list } \\
\text { memory } \\
\text { BCSB }\end{array}$} & $\mathrm{r}=0,346$ & $r=0,093$ & $\mathrm{r}=0,399$ & $\mathrm{r}=-0,448$ & $r=-0,099$ & $r=-0,201$ & $r=0294$ & $\mathrm{r}=-0,11$ \\
\hline & $p=0,189$ & $p=0,731$ & $p=0,126$ & $p=0,082$ & $p=0,715$ & $p=0,455$ & $p=0,27$ & $\mathrm{p}=0,685$ \\
\hline \multirow{2}{*}{$\begin{array}{l}\text { Word list } \\
\text { recall } \\
\text { CERAD }\end{array}$} & $r=0,045$ & $r=0,225$ & $r=0,277$ & $r=-0,032$ & $\mathrm{r}=0,265$ & $r=0,15$ & $r=0,406$ & $r=0,057$ \\
\hline & $p=0,868$ & $p=0,402$ & $p=0299$ & $p=0,906$ & $p=0,321$ & $p=0,671$ & $p=0,119$ & $p=0,833$ \\
\hline \multirow{2}{*}{$\begin{array}{l}\text { Delay } \\
\text { memory } \\
\text { BCSB }\end{array}$} & $\mathrm{r}=0,494$ & $r=0,09$ & $\mathrm{r}=0,368$ & $r=0,183$ & $\mathrm{r}=0,282$ & $r=-0,0<6$ & $r=0,564^{\circ}$ & $r=0,097$ \\
\hline & $\mathrm{p}=0,052$ & $\mathrm{p}=0,724$ & $p=0,161$ & $p=0,496$ & $\mathrm{p}=0,289$ & $\mathrm{p}=0,923$ & $p=0,023$ & $\mathrm{p}=0,72$ \\
\hline \multirow{2}{*}{$\begin{array}{l}\text { Constructio } \\
\text { nal praxis }\end{array}$} & $r=-0,332$ & $r=-0,023$ & $r=0,081$ & $r=-0,205$ & $r=0,281$ & $r=0,091$ & $r=-0,194$ & $r=0,022$ \\
\hline & $p=0,208$ & $p=0,933$ & $p=0,766$ & $p=0,446$ & $p=0,293$ & $p=0,737$ & $p=0,471$ & $p=0,937$ \\
\hline \multirow{2}{*}{ Abstraction } & $r=0,085$ & $r=-0,162$ & $r=0,1$ & $r=0,099$ & $r=0,391$ & $r=0,300$ & $r=0267$ & $r=0,052$ \\
\hline & $p=0,754$ & $p=0,549$ & $p=0,713$ & $p=0,714$ & $p=0,134$ & $p=0,253$ & $p=0,317$ & $\mathrm{p}=0,849$ \\
\hline \multirow{2}{*}{ Direct digit } & $\mathrm{r}=-0,214$ & $\mathrm{r}=0,197$ & $r=0,136$ & $r=0,167$ & $r=0,146$ & $\mathrm{r}=0,621^{\circ}$ & $r=-0205$ & $r=0,304$ \\
\hline & $\mathrm{p}=0,427$ & $p=0,465$ & $p=0,614$ & $p=0.537$ & $p=0,589$ & $p=0,01$ & $p=0,445$ & $p=0,252$ \\
\hline \multirow{2}{*}{ Reverse digit } & $r=0,497$ & $r=0,013$ & $\mathrm{r}=0,178$ & $\mathrm{r}=-0,328$ & $r=0,386$ & $r=0,131$ & $r=0,148$ & $r=0,218$ \\
\hline & $p=0,050$ & $p=0, \% 1$ & $p=0.51$ & $p=0,216$ & $p=0,14$ & $p=0, \notin 29$ & $p=0.584$ & $p=0,417$ \\
\hline \multirow{2}{*}{$\begin{array}{c}\text { Clock } \\
\text { drawing test }\end{array}$} & $r=0,341$ & $r=-0,055$ & $r=0,382$ & $r=0,233$ & $r=-0,047$ & $r=0,177$ & $r=0242$ & $r=0,356$ \\
\hline & $p=0,196$ & $p=0,838$ & $p=0,144$ & $p=0,386$ & $p=0,863$ & $p=0,562$ & $p=0,366$ & $p=0,176$ \\
\hline \multirow{2}{*}{$\begin{array}{l}\text { Verbal } \\
\text { Flvency }\end{array}$} & $\mathrm{r}=0.529$ & $r=-0,076$ & $r=0,257$ & $r=-0,038$ & $r=0,539$ & $r=0,044$ & $r=0,317$ & $r=0,124$ \\
\hline & $\mathrm{p}=0,035$ & $p=0,781$ & $p=0,337$ & $p=0,888$ & $p=0,031$ & $p=0,872$ & $p=0232$ & $p=0,647$ \\
\hline
\end{tabular}

Fig. 7. Statistic convergence analysis of the first experiment.

Another study [75], with 39 older people that aimed to analyze their feelings towards using the game platform "Viajando pelo mundo" ("Traveling around the world"), identified that positive feelings were more evidenced than the negative. However, the study observed that negative feelings are directly related to the game difficulty level; also, these feelings show up more frequently when the game being played demands more interaction, such as puzzles in which they need to move and put together the pieces of an image.

In the same study, researchers observed that the participants experienced negative feelings when playing a game based on Tangram, in which older adults needed to touch and drag geometric shapes to assemble an image. The participants [75] voiced their feelings many times, showing confusion and irritation: "Won't this piece turn?"; "But this doesn't have the same color"; "Can't I skip this one?"

The study [75] used an extensive protocol of cognitive tests commonly administered. As expected, there was a correlation between them, since they are battery of assessments already validated in many academic research. The researchers also administered a cognitive digital test to verify its possible correlation with validated protocols, but the anxiety and the negative feelings caused by using digital games that demand 
more interaction (and consequently let the users more tired at the end) might have interfered with the performance of the participants.

\section{B. Results of the Second Experiment}

We conducted a second experiment aiming to achieve a significant convergence. One of the initiatives taken for this was to reduce the time spent to complete the battery' tests, decreasing the number of tests and choosing tests that required less adaptation when transposed digitally. These objectives are both results of our observations of the first experiment, which lasted a long time (1-2 hours) and had too many adaptations in comparison with validated tests.

In this second experiment, we did not apply an UEQ, as we wanted to make evaluations shorter and less exhausting. Therefore, the results of this experiment are shown in Figure 8 and we are able to compare them to those of the first experiment.

There was a significant convergence of results from the 23 participants of the digital test and the batteries of paper-based tests. This suggests that it is possible to use digital games to achieve similar results of those of validated tests commonly used by health professionals. This correlation $(\mathrm{r}>0.5 \mathrm{e} \mathrm{p}<$ 0.05 ) can be seen in 20 out of 55 values in Figure 8 (36.36\% - highlighted on the figure).

\section{DISCUSSION}

The Brazilian population of "digitally included" older adults is composed of people aged 50 to 65 years that probably were introduced to digital technologies on their work environments or were personally interested in knowing more about it. This generation of people (known as baby boomers) values autonomy and is highly preoccupied with life quality.

The results presented in the present study allow us to see this group as potential users of digital games, not only because those games are entertaining, but also because of their healthy bias.

We consider that it was fundamental, during the definition of experiments, to observe the characteristics of the participants and to create the prototypes following a development process. It was important because we used the process of Unified Design and incorporated the evaluation of usability and accessibility that our target audience demands. In fact, working with the several different changes that affect the human body during the ageing process is a challenge. Therefore, the project of interfaces and interactions in digital games must consider the necessities of users with cognitive or physical impairment, for this is a heterogeneous group that has different levels of needs.

We observed, during the present study, that digital games that demand a rigid and generalized application of accessibility criteria might make the experience not viable for some users. Hence, we must identify the target audience profile to comprehend which is the best dynamic adaptation mechanism of gameplay, so we can offer a game with the most adapted presentation possible.

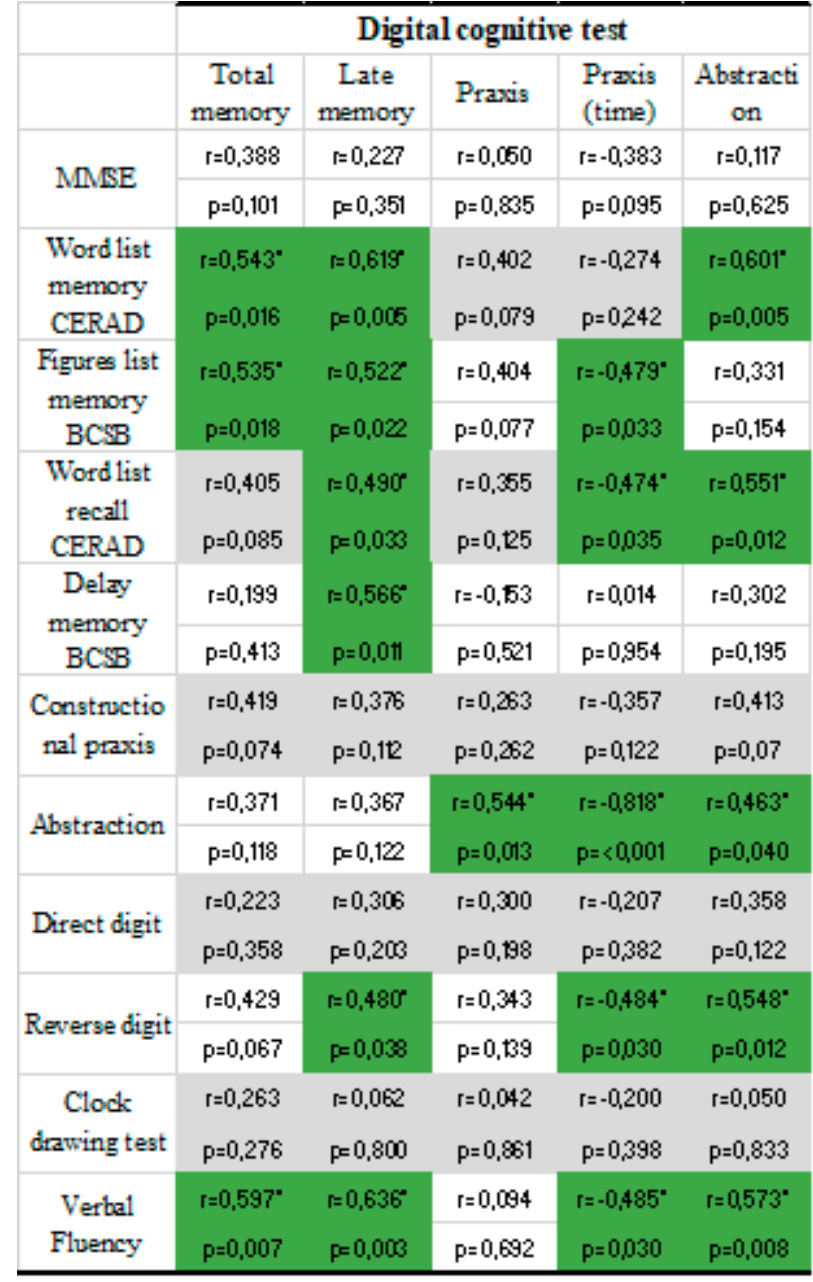

Fig. 8. Statistic convergence analysis of the second experiment.

From the interaction of the player with the game, we may consider a personalized adaptation of the interface, for example, of functions depending on time (performance). We believe that the cognitive test, which aims to recognize the characteristics of the evaluated user, is a technological tool that can direct this user to a productive experience that is connected to his or her real needs.

\section{CONCLUSiOnS AND Future Work}

Serious games are a relevant instrument with various applications, such as supporting activities in health field. Some of the main benefits of the digital model compared to the traditional paper model are: (a) substantial increase in the possibility of testing variation, and thus the opportunity for continuous, bias-free interventions represented by repeating the same task, $(b)$ storage on digital media or computer networks, facilitating retrieval and analysis, (c) data collection at interaction time without the bias of the evaluator, $(d)$ increase of the collected data variables, contributing to evaluation results that are more sensitive to small variations and (e) possibility of self-administered tests, promoting a low cost 
of application, since it does not have to travel to specialized laboratories.

In the present study, we investigated the use of serious games as a tool for cognitive evaluation of older people in Brazil. In fact, digital technologies are a reality today and many older adults have already been introduced to the digital world in their familiar or working environment.

Therefore, it seems natural to connect the potential of serious games to the needs of society, for the population is rapidly growing. In this context, our research shows that it is possible to achieve similar results to those of validated paperbased cognitive tests using a digital game adapted to the needs of the older person.

In future works, we will analyze the data from the interviews of both experiments (Table II), which identified the habits of participants. This analysis will allow us to consider and offer a directed narrative to this community in future cognitive training games we aim to develop. Thus, we intend to personalize these future games according to the results of the digital cognitive test that was administered to the user previously.

\section{ACKNOWLEDGMENT}

The present study was supported by the grants 2016/010090 and 2017/14952-4, São Paulo Research Foundation (FAPESP).

\section{REFERENCES}

[1] United Nations, Department of Economic and Social Affairs, Population Division, "World population ageing 2015 (st/esa/ser. a/390)," 2015.

[2] "Ibge - projeção da população," https://bit.ly/2U8XeZt, accessed: 2018$07-10$.

[3] J. Cole, "The epidemiological transition," Planetary Health: Human Health in an Era of Global Environmental Change, p. 58, 2019.

[4] L. A. A. Neto, "Muito além da transição epidemiológica: doenças crônicas no século xx," História, Ciências, Saúde-Manguinhos, vol. 26, no. 1, pp. 353-355, 2019.

[5] T. Dua, K. M. Seeher, S. Sivananthan, N. Chowdhary, A. M. Pot, and S. Saxena, "World health organization's global action plan on the public health response to dementia 2017-2025," Alzheimer's \& Dementia: The Journal of the Alzheimer's Association, vol. 13, no. 7, pp. P1450-P1451, 2017.

[6] E. Nichols, C. E. Szoeke, S. E. Vollset, N. Abbasi, F. Abd-Allah, J. Abdela, M. T. E. Aichour, R. O. Akinyemi, F. Alahdab, S. W. Asgedom et al., "Global, regional, and national burden of alzheimer's disease and other dementias, 1990-2016: a systematic analysis for the global burden of disease study 2016," The Lancet Neurology, vol. 18, no. 1, pp. 88-106, 2019.

[7] M. Scazufca, P. R. Menezes, H. P. Vallada, A. L. Crepaldi, M. PastorValero, L. M. S. Coutinho, V. D. Di Rienzo, and O. P. Almeida, "High prevalence of dementia among older adults from poor socioeconomic backgrounds in são paulo, brazil," International Psychogeriatrics, vol. 20, no. 2, p. 394-405, 2008.

[8] M. S. Boff, F. S. Sekyia, and C. M. de Campos Bottino, "Revisão sistemática sobre prevalência de demência entre a população brasileira," Revista de Medicina, vol. 94, no. 3, pp. 154-161, 2015.

[9] M. H. N. Chagas, R. M. P. Pessoa, and O. P. Almeida, "Comparison of dsm-iv and dsm-5 dementia criteria among older people living in a community sample," International journal of geriatric psychiatry, vol. 33, no. 5, pp. 801-802, 2018.

[10] C. Burla, A. A. Camarano, S. Kanso, D. Fernandes, and R. Nunes, "Panorama prospectivo das demências no Brasil: um enfoque demográfico," Ciência \& Saúde Coletiva, vol. 18, pp. 2949 - 2956, 10 2013. [Online]. Available: http://www.scielo.br/scielo.php?script=sci_ arttext\&pid=S1413-81232013001000019\&nrm=iso
[11] L. PY, E. de Freitas, and M. DO GORZONI, Tratado de geriatria $e$ gerontologia. Guanabara Koogan, 2006. [Online]. Available: https://books.google.com.br/books?id=AnIZPwAACAAJ

[12] D. Ferreira, Y. Molina, A. Machado, E. Westman, L.-O. Wahlund, A. Nieto, R. Correia, C. Junqué, L. Díaz-Flores, and J. Barroso, "Cognitive decline is mediated by gray matter changes during middle age," Neurobiology of Aging, vol. 35, no. 5, pp. 1086 - 1094, 2014. [Online]. Available: http://www.sciencedirect.com/science/article/ pii/S0197458013005630

[13] J. Mishra, C. Rolle, and A. Gazzaley, "Neural plasticity underlying visual perceptual learning in aging," Brain Research, vol. 1612, pp. 140-151, Jul. 2015. [Online]. Available: https://doi.org/10.1016/j. brainres.2014.09.009

[14] E. C. dos Santos Assef, A. G. S. Capovilla, and F. C. Capovilla, "Computerized stroop test to assess selective attention in children with attention deficit hyperactivity disorder," The Spanish journal of psychology, vol. 10, no. 01, pp. 33-40, May 2007. [Online]. Available: https://doi.org/10.1017/s1138741600006296

[15] C. A. M. Junior and L. B. R. Melo, "Integração de três conceitos: função executiva, memória de trabalho e aprendizado," Psicologia: Teoria e Pesquisa, vol. 27, no. 3, pp. 309-314, Sep. 2011. [Online]. Available: https://doi.org/10.1590/s0102-37722011000300006

[16] E. Tulving, "Episodic memory: From mind to brain," Annual review of psychology, vol. 53, pp. 1-25, 022002.

[17] D. C. Mathur and B. Wilshire, "William james and phenomenology: A study of the "principles of psychology."," Philosophy and Phenomenological Research, vol. 30, no. 1, p. 142, Sep. 1969. [Online]. Available: https://doi.org/10.2307/2105931

[18] C. W. Lamb, J. F. Hair, and C. McDaniel, Essentials of Marketing (Available Titles CengageNOW). SouthWestern College Pub, 2008. [Online]. Available: https://www. amazon.com/Essentials-Marketing-Available-Titles-CengageNOW/ $\mathrm{dp} / 0324656203$ ?SubscriptionId=AKIAIOBINVZYXZQZ2U3A\&tag= chimbori05-20\&linkCode $=x m 2 \&$ camp $=2025 \&$ creative $=165953 \&$ creativeASIN $=0324656203$

[19] C. R. B. Grden, M. F. C. Barreto, J. A. V. de Sousa, J. A. Chuertniek, P. M. Reche, and P. K. de Oliveira Borges, "Association between physical frailty and cognitive scores in older adults," Revista da Rede de Enfermagem do Nordeste, vol. 16, no. 3, Jun. 2015. [Online]. Available: https://doi.org/10.15253/2175-6783.2015000300012

[20] M. Canevelli, M. Cesari, and G. A. van Kan, "Frailty and cognitive decline," Current Opinion in Clinical Nutrition and Metabolic Care, vol. 18, no. 1, pp. 43-50, Jan. 2015. [Online]. Available: https://doi.org/10.1097/mco.0000000000000133

[21] T. Tong, M. Chignell, M. C. Tierney, and J. Lee, "A serious game for clinical assessment of cognitive status: Validation study," JMIR Serious Games, vol. 4, no. 1, p. e7, May 2016. [Online]. Available: https://doi.org/10.2196/games.5006

[22] D. Grammenos, A. Savidis, and C. Stephanidis, "Designing universally accessible games," Comput. Entertain., vol. 7, pp. 8:1-8:29, Feb. 2009. [Online]. Available: http://doi.acm.org/10.1145/1486508.1486516

[23] S. De Freitas, "Are games effective learning tools? a review of educational games," Journal of Educational Technology \& Society, vol. 21, no. 2, pp. 74-84, 2018.

[24] M. Graafland and M. Schijven, "How serious games will improve healthcare," in Digital Health. Springer, 2018, pp. 139-157.

[25] J. P. Gee, "What video games have to teach us about learning and literacy," Computers in Entertainment, vol. 1, no. 1, p. 20, Oct. 2003. [Online]. Available: https://doi.org/10.1145/950566.950595

[26] D. R. Michael and S. L. Chen, Serious games: Games that educate, train, and inform. Muska \& Lipman/Premier-Trade, 2005.

[27] F. L. Greitzer, O. A. Kuchar, and K. Huston, "Cognitive science implications for enhancing training effectiveness in a serious gaming context," Journal on Educational Resources in Computing (JERIC), vol. 7, no. 3, p. 2, 2007.

[28] D. G. Frederik, M. Peter, and V. L. Jan, "Uncharted waters?: exploring experts' opinions on the opportunities and limitations of serious games for foreign language learning," in Proceedings of the 3rd International Conference on Fun and Games. ACM, 2010, pp. 107-115.

[29] S.-T. Chen, Y.-G. L. Huang, and I.-T. Chiang, "Using somatosensory video games to promote quality of life for the elderly with disabilities," in 2012 IEEE Fourth International Conference On Digital Game And Intelligent Toy Enhanced Learning. IEEE, 2012, pp. 258-262. 
[30] "Programa de estimulação cognitiva em idosos institucionalizados," http://www.psicologia.pt/artigos/ver_artigo.php?codigo=a0623, accessed: 2017-07-09.

[31] A. C. S. Torres, "Cognitive effects of video games on old people," International Journal on Disability and Human Development, vol. 10, no. 1, pp. 55-58, 2011.

[32] J. Wiemeyer and A. Kliem, "Serious games in prevention and rehabilitation-a new panacea for elderly people?" European Review of Aging and Physical Activity, vol. 9, no. 1, p. 41, 2012.

[33] Y. Jung, K. J. Li, N. S. Janissa, W. L. C. Gladys, and K. M. Lee, "Games for a better life: effects of playing wii games on the well-being of seniors in a long-term care facility," in Proceedings of the Sixth Australasian Conference on Interactive Entertainment. ACM, 2009, p. 5.

[34] S. Valladares-Rodríguez, R. Pérez-Rodríguez, L. Anido-Rifón, and M. Fernández-Iglesias, "Trends on the application of serious games to neuropsychological evaluation: a scoping review," Journal of biomedical informatics, vol. 64, pp. 296-319, 2016.

[35] M. A. Espeland, J. A. Katula, J. Rushing, A. F. Kramer, J. M. Jennings, K. M. Sink, N. K. Nadkarni, K. F. Reid, C. M. Castro, T. Church et al., "Performance of a computer-based assessment of cognitive function measures in two cohorts of seniors," International journal of geriatric psychiatry, vol. 28, no. 12, pp. 1239-1250, 2013.

[36] M. Folstein, "A practical method for grading the cognitive state of patients for the children," J Psychiatr res, vol. 12, pp. 189-198, 1975.

[37] S. Brucki, R. Nitrini, P. Caramelli, P. H. Bertolucci, and I. H. Okamoto, "Suggestions for utilization of the mini-mental state examination in brazil," Arquivos de neuro-psiquiatria, vol. 61, no. 3B, pp. 777-781, 2003.

[38] É. Castro-Costa, C. Fuzikawa, E. Uchoa, J. O. A. Firmo, and M. F. LimaCosta, "Norms for the mini-mental state examination: adjustment of the cut-off point in population-based studies (evidences from the bambui health aging study)," Arquivos de neuro-psiquiatria, vol. 66, no. 3A, pp. 524-528, 2008.

[39] R. Nitrini, B. Lefèvre, S. Mathias, P. Caramelli, P. Carrilho, N. Sauaia, E. Massad, C. Takiguti, I. S. Da, and C. Porto, "Neuropsychological tests of simple application for diagnosing dementia," Arquivos de neuropsiquiatria, vol. 52, no. 4, pp. 457-465, 1994.

[40] R. Nitrini, P. Caramelli, E. HERRERA, C. S. Porto, H. CharchatFichman, M. T. Carthery, L. T. Takada, and E. P. Lima, "Performance of illiterate and literate nondemented elderly subjects in two tests of longterm memory," Journal of the International Neuropsychological Society, vol. 10, no. 4, pp. 634-638, 2004.

[41] A. L. Dickson, "Book review: Lezak, muriel deutsch,(1983). neuropsychological assessment . new york: Oxford university press," Journal of Psychoeducational Assessment, vol. 4, no. 1, pp. 91-92, 1986.

[42] E. Strauss, E. M. Sherman, O. Spreen et al., A compendium of neuropsychological tests: Administration, norms, and commentary. American Chemical Society, 2006.

[43] C. Fuzikawa, M. F. Lima-Costa, E. Uchoa, S. M. Barreto, and K. Shulman, "A population based study on the intra and inter-rater reliability of the clock drawing test in brazil: the bambuí health and ageing study," International journal of geriatric psychiatry, vol. 18, no. 5, pp. 450-456, 2003.

[44] I. Aprahamian, J. E. Martinelli, A. L. Neri, and M. S. Yassuda, "The accuracy of the clock drawing test compared to that of standard screening tests for alzheimer's disease: results from a study of brazilian elderly with heterogeneous educational backgrounds," International Psychogeriatrics, vol. 22, no. 1, pp. 64-71, 2010.

[45] S. M. D. Brucki and M. S. G. Rocha, "Category fluency test: effects of age, gender and education on total scores, clustering and switching in brazilian portuguese-speaking subjects," Brazilian journal of medical and biological research, vol. 37, no. 12, pp. 1771-1777, 2004.

[46] J. C. Morris, A. Heyman, R. Mohs, J. Hughes, G. Van Belle, G. Fillenbaum, E. Mellits, and C. Clark, "The consortium to establish a registry for alzheimer's disease (cerad): I. clinical and neuropsychological assessment of alzheimer's disease." Neurology, 1989.

[47] P. H. F. Bertolucci, I. H. Okamoto, S. M. D. Brucki, M. O. Siviero, J. Toniolo Neto, and L. R. Ramos, "Applicability of the cerad neuropsychological battery to brazilian elderly," Arquivos de neuro-psiquiatria, vol. 59, no. 3A, pp. 532-536, 2001.

[48] W. G. Rosen, R. C. Mohs, and K. L. Davis, "A new rating scale for alzheimer's disease." The American journal of psychiatry, 1984.

[49] M. Roth, F. A. Huppert, C. Q. Mountjoy, and E. Tym, CAMDEX-R Boxed Set: The Revised Cambridge Examination for Mental Disorders of the
Elderly. Cambridge University Press, 1999. [Online]. Available: https: //www.amazon.com/CAMDEX-R-Boxed-Set-Cambridge-Examination/ $\mathrm{dp} / 0521462614$ ?SubscriptionId=AKIAIOBINVZYXZQZ2U3A\&tag= chimbori05-20\&linkCode $=x m 2 \&$ camp $=2025 \&$ creative $=165953 \&$ creativeASIN $=0521462614$

[50] C. G. Kohler, T. H. Turner, R. E. Gur, and R. C. Gur, "Recognition of facial emotions in neuropsychiatric disorders," CNS spectrums, vol. 9, no. 4, pp. 267-274, 2004.

[51] "Diagnostic and statistical manual of mental disorders (dsm-5)," https: //www.psychiatry.org/psychiatrists/practice/dsm, accessed: 2018-07-10.

[52] M. T. Atkinson, S. Gucukoglu, C. H. Machin, and A. E. Lawrence, "Making the mainstream accessible: What's in a game?" in International Conference on Computers for Handicapped Persons. Springer, 2006, pp. 380-387.

[53] D. Grammenos, "Game over: learning by dying," in Proceedings of the SIGCHI Conference on Human Factors in Computing Systems. ACM, 2008, pp. 1443-1452.

[54] K. Bierre, J. Chetwynd, B. Ellis, D. M. Hinn, S. Ludi, and T. Westin, "Game not over: Accessibility issues in video games," in Proc. of the 3rd International Conference on Universal Access in Human-Computer Interaction, 2005, pp. 22-27.

[55] W. H. Organization et al., "International classification of impairments, disabilities, and handicaps: a manual of classification relating to the consequences of disease, published in accordance with resolution wha29. 35 of the twenty-ninth world health assembly, may 1976," 1980.

[56] W. How, "Develops accessibility guidelines through the w3c process: Milestones and opportunities to contribute. web accessibility initiative. w3c," 2018.

[57] B. Caldwell, M. Cooper, L. G. Reid, and G. Vanderheiden, "Web content accessibility guidelines (wcag) 2.0," WWW Consortium (W3C), 2008.

[58] H. Petrie, A. Savva, and C. Power, "Towards a unified definition of web accessibility," in Proceedings of the 12th Web for all Conference. ACM, 2015, p. 35.

[59] B. Yuan, E. Folmer, and F. C. Harris, "Game accessibility: a survey," Universal Access in the Information Society, vol. 10, no. 1, pp. 81-100, 2011.

[60] R. Ossmann and K. Miesenberger, "Guidelines for the development of accessible computer games," 01 2006, pp. 403-406.

[61] B. Ellis, G. Ford-Williams, L. Graham, D. Grammenos, I. Hamilton, E. Lee, J. Manion, and T. Westin, "Game accessibility guidelines: A straightforward reference for inclusive game design," 2017.

[62] D. Grammenos, A. Savidis, and C. Stephanidis, "Unified design of universally accessible games," in Universal Access in Human-Computer Interaction. Applications and Services, C. Stephanidis, Ed. Berlin, Heidelberg: Springer Berlin Heidelberg, 2007, pp. 607-616.

[63] R. G. O. Rocha, "Uso de tablets como ferramenta facilitadora em projetos de inclusão digital de idosos," 2013.

[64] Estatuto do Idoso, "Lei no 10.741, de $1^{\circ}$ de outubro de 2003," Dispõe sobre a Política Nacional do Idoso, e dá outras providências. Diário Oficial da União, Brasília, vol. 3, 2003.

[65] B. Bonnechère, m. Van Vooren, J.-C. Bier, S. De Breucker, O. Van Hove, S. Van Sint Jan, V. Feipel, and B. Jansen, "The use of mobile games to assess cognitive function of elderly with and without cognitive impairment." Journal of Alzheimer's Disease, vol. 64, no. 4, pp. 12851293, 72018.

[66] B. Laugwitz, T. Held, and M. Schrepp, "Construction and evaluation of a user experience questionnaire," in Symposium of the Austrian HCI and Usability Engineering Group. Springer, 2008, pp. 63-76.

[67] A. de Lima Salgado, L. A. do Amaral, R. P. de Mattos Fortes, M. H. N. Chagas, and G. Joyce, "Addressing mobile usability and elderly users: Validating contextualized heuristics," in International Conference of Design, User Experience, and Usability. Springer, 2017, pp. 379-394.

[68] R. P. M. Fortes, A. de Lima Salgado, F. de Souza Santos, L. A. do Amaral, and E. A. N. da Silva, "Game accessibility evaluation methods: A literature survey," in International Conference on Universal Access in Human-Computer Interaction. Springer, 2017, pp. 182-192.

[69] IGDA, "Igda game access sig," nov 2010. [Online]. Available: https://igda-gasig.org/

[70] M. L. Chaves, C. C. Godinho, C. S. Porto, L. Mansur, M. T. Carthery Goulart, M. S. Yassuda, and R. Beato, "Doença de alzheimer. avaliação cognitiva, comportamental e funcional," Dementia \& Neuropsychologia, vol. 5, no. 1, 2011.

[71] M. S. Kanbar, "Tangram game assembly," Nov. 3 1981, uS Patent $4,298,200$. 
[72] I. Rabelo, S. Pacanaro, I. Leme, R. Ambiel, and G. Alves, "Teste não verbal de inteligência geral-beta iii-subtestes raciocínio matricial e códigos," Manual Técnico. São Paulo: Casa do Psicólogo, 2011.

[73] F. O. Alves, A. L. C. Zaninotto, E. C. Miotto, M. C. S. d. Lucia, and M. Scaff, "Avaliação da atenção sustentada e alternada em uma amostra de adultos saudáveis com alta escolaridade," Psicologia Hospitalar, vol. 8, no. 2, pp. 89-105, 2010.

[74] A. McLaughlin, M. Gandy, J. Allaire, and L. Whitlock, "Putting fun into video games for older adults," Ergonomics in Design, vol. 20, no. 2, pp. 13-22, 2012.

[75] A. D. Evelin, K. C. da Silva, O. F. Neves, L. Ishitani, and C. N. Nobre, "Experiência emocional de idosos com jogos digitais para smartphonesum estudo de caso do jogo brasileiro viajando pelo mundo." 